\title{
The Distribution of Heptose and 2-Keto-3-deoxy-octonate in Bacteroidaceae
}

\author{
By T. HOFSTAD \\ Department of Microbiology, School of Medicine, \\ The University of Bergen, $N-5000$ Bergen, Norway
}

(Received 24 June I974; revised 9 August 1974)

\begin{abstract}
SUMMARY
A survey of phenol-water extracts of 17 different Fusobacterium and Bacteroides species, including subspecies, and of Leptotrichia buccalis has been carried out using colorimetric and chromatographic techniques to demonstrate the presence of heptose and 2-keto-3-deoxy-octonate. Both sugars were found in the water phase of the extracts from Fusobacterium strains and Leptotrichia buccalis. Neither heptose nor 2-keto-3-deoxy-octonate were detected in the water or the phenol phase of extracts from strains classified as Bacteroides.
\end{abstract}

\section{INTRODUCTION}

Generic classification of anaerobic Gram-negative non-sporeforming bacilli depends primarily on metabolic activities (Anaerobe Laboratory Manual, 1972; Subcommittee, 1970). Fusobacterium, including species formerly classified as Sphaerophorus (Bergey's Manual of Determinative Bacteriology, 1957), produces large amounts of butyric acid from glucose while most Bacteroides species do not. Some $B$. melaninogenicus strains ferment certain amino acids with formation of butyric acid, but in addition isobutyric, isovaleric and propionic acids are produced (Wahren \& Gibbons, 1970). The same four fatty acids are also present in cultures of B. praeacutus and B. putredinum. Leptotrichia buccalis ferments glucose and a number of other carbohydrates with the formation of lactic acid.

Endotoxic lipopolysaccharide (LPS) has been prepared in this laboratory from oral strains of Fusobacterium (Kristoffersen \& Hofstad, 1970) and Bacteroides melaninogenicus (Hofstad, I968; Hofstad \& Kristoffersen, I97I $a$ ), from a single strain of $B$. fragilis (Hofstad \& Kristoffersen, I970a) and from three strains classified as Sphaerophorus necrophorus (Hofstad \& Kristoffersen, I97I $b$ ). Lipopolysaccharide from Fusobacterium and from one of the three S. necrophorus strains contained heptose and small amounts of 2-keto-3-deoxy-octonate (KDO). These sugars were not detected in LPS isolated from $B$. melaninogenicus, from the $B$. fragilis strain or from the remaining two strains of $S$. necrophorus (ATCCI 2290 and Institut Pasteur 3328), which, however, were later shown to belong to Bacteroides (Werner, 1970; Hofstad, unpublished). When present in LPS, heptose is a constituent of the basic polysaccharide core (Lüderitz, Staub \& Westphal, I966), while KDO provides the bridge between this core and lipid A (Osborn, 1963). These studies thus suggested a difference in wall chemistry between Fusobacterium and Bacteroides which might serve as a useful taxonomic criterion. Several other well-characterized strains representing separate Fusobacterium and Bacteroides species as well as two strains of Leptotrichia buccalis have therefore been examined for the presence of heptose and KDO. 
Table I. Distribution of heptose in phenol-water extracts of Bacteroides, Fusobacterium and Leptotrichia buccalis

\begin{tabular}{|c|c|c|c|c|c|c|c|}
\hline \multirow[b]{3}{*}{ Species } & \multirow[b]{3}{*}{ Strain } & \multicolumn{3}{|c|}{ Water phase } & \multicolumn{3}{|c|}{ Phenol phase } \\
\hline & & \multirow{2}{*}{$\begin{array}{l}\text { Dische's } \\
\text { reaction }\end{array}$} & \multicolumn{2}{|c|}{ Chromatography } & \multirow{2}{*}{$\begin{array}{l}\text { Dische's } \\
\text { reaction }\end{array}$} & \multicolumn{2}{|c|}{ Chromatography } \\
\hline & & & Paper & GLC & & Paper & $\overline{\text { GLC }}$ \\
\hline B. coagulans & VPI3476 & - & - & - & + & - & \\
\hline \multicolumn{8}{|l|}{ B. fragilis } \\
\hline ss. fragilis & Lille $\mathrm{E} 323$ & - & - & & + & - & \\
\hline ss. fragilis & NCTC9343 & - & - & - & + & - & - \\
\hline ss. fragilis & VPI5807 & - & - & & + & - & \\
\hline ss. distasonis & ATCC 8503 & - & - & & + & - & \\
\hline ss. thetaiotaomicron & ATCC I 2290 & - & - & & + & - & \\
\hline ss. thetaiotaomicron & Lille 59 & - & - & & + & - & \\
\hline ss. thetaiotaomicron & VPI5333 & - & - & & + & - & \\
\hline ss. vulgatus & ATCC 8482 & - & - & & + & - & \\
\hline B. furcosus & VP13255 & - & - & & + & - & \\
\hline B. hypermegas & VPI2366 $=$ ATCC25560 & - & - & & + & - & \\
\hline \multicolumn{8}{|l|}{ B. melaninogenicus } \\
\hline ss. intermedius & VPI4I I97 = ATCC256II & - & - & - & + & - & - \\
\hline ss. intermedius & VPI779IC & - & - & & + & - & \\
\hline ss. melaninogenicus & VPI238I $=$ ATCC25845 & - & - & & + & - & \\
\hline ss. melaninogenicus & VPI4I96 $=$ ATCC25847 & - & - & - & + & - & - \\
\hline ss. asaccharolyticus & VPI4199 $=$ ATCC25846 & - & - & - & + & - & - \\
\hline \multicolumn{8}{|l|}{ B. oralis } \\
\hline ss. oralis & VPI5832 & - & - & & + & - & \\
\hline ss. oralis & VPI7570A & - & - & & + & - & \\
\hline B. putredinum & VPI4998-I & - & - & - & + & - & \\
\hline B. preacutus & VPIO2I $7-I$ & - & - & & + & - & \\
\hline B. serpens & VPI0950-I & - & - & & + & - & \\
\hline F. mortiferum & $\mathrm{VPIO} 473=\mathrm{ATCC} 9817$ & + & + & & & & \\
\hline F. naviforme & VPI4877 & + & + & & & & \\
\hline F. necrogenes & VPI2368 $=$ ATCC25556 & + & + & & & & \\
\hline F. necrophorum & VPI616I & + & + & & & & \\
\hline F. nucleatum & VPI $4355=$ ATCC25586 & + & + & & & & \\
\hline F. nucleatum & ATCCI 0953 & + & + & & & & \\
\hline F.plauti & VPI4I45 & + & + & & & & \\
\hline F.russi & VPIO3O7 & + & + & & & & \\
\hline$F$. varium & VPIO499A & + & + & & & & \\
\hline F. varium & ATCC850I & + & + & & & & \\
\hline L. buccalis & LII* & + & + & & & & \\
\hline L. buccalis & L66* & + & + & & & & \\
\hline
\end{tabular}

\section{METHODS}

Organisms. The strains examined (Table I) were obtained from: American Type Culture Collection, Rockville, Maryland, U.S.A. (ATCC); Institut Pasteur de Lille, France (Lille); National Collection of Type Cultures, Central Public Health Laboratory, London (NCTC); and the Virginia Polytechnic Institute and State University, Blacksburg, Virginia, U.S.A. (vPI).

Cultural conditions. Cultures were grown in 500 or $1000 \mathrm{ml} \mathrm{screw-cap}$ bottles filled to the top with the following medium (g/l): whale meat extract (Rieber \& Sön A/S, Bergen, Norway), IO; proteose peptone (Oxoid), I5; NaCl, $5 ; \mathrm{KH}_{2} \mathrm{PO}_{4}, \mathrm{I} \cdot 5 ; \mathrm{Na}_{2} \mathrm{HPO}_{4} .2 \mathrm{H}_{2} \mathrm{O}, 3.5$; 
$\left(\mathrm{NH}_{4}\right)_{2} \mathrm{SO}_{4}, 0.5$; yeast extract (Oxoid), 3 ; L-cysteine $\mathrm{HCl}, \mathrm{I}$; and glucose, $5 ; \mathrm{pH} 7 \cdot 0$. For Bacteroides oralis, B. melaninogenicus and Leptotrichia buccalis the medium was supplemented with $5 \%$ horse serum. The organisms were harvested by centrifuging cultures in the stationary phase of growth (after $\mathrm{I}$ to 3 days at $37^{\circ} \mathrm{C}$ ).

Extraction and purification methods. Washed organisms were extracted with constant stirring with $45 \%$ aqueous phenol for $15 \mathrm{~min}$ at room temperature (approx. $22{ }^{\circ} \mathrm{C}$ ). After centrifuging for $30 \mathrm{~min}$ at $2500 \mathrm{~g}$ the water phase was pipetted off, dialysed against tap water and freeze-dried. Lipopolysaccharide was purified from the water phase of some strains by ultracentrifuging (I00000 $\mathrm{g}$ for $60 \mathrm{~min}$ ), and treatment with deoxyribonuclease and ribonuclease (Hofstad \& Kristoffersen, 1970a). The phenol phase was freed from particulate materials by addition of an equal volume of $90 \%$ phenol and centrifuging ( $12000 \mathrm{~g}$ for $30 \mathrm{~min}$ ). Three volumes of sodium acetate-methanol ( $\mathrm{I} \mathrm{ml} \mathrm{of} \mathrm{saturated} \mathrm{sodium}$ acetate in $100 \mathrm{ml}$ of methanol) were then added to the cleared phenol phase, and the mixture left at $4{ }^{\circ} \mathrm{C}$ overnight. The precipitate was centrifuged, taken up with water and dialysed. Following dialysis for 4 days against tap water the suspension within the dialysis bag was freeze-dried without further treatment.

Colorimetric determinations. Heptose was estimated by the sulphuric acid cysteine reaction as described by Dische (1953), or with the modifications of Osborn (1963) or Wright \& Rebers (1972). The absorbance of the reaction mixture was examined over the range 450 to $600 \mathrm{~nm}$. A peak or a shoulder at 500 to $510 \mathrm{~nm}$ was taken as a qualitative indication of heptose. The presence of KDO was investigated by the thiobarbituric acid method (Weissbach \& Hurwitz, I959). The absorbance was examined over the range of 500 to $600 \mathrm{~nm}$, and a peak or a shoulder at $550 \mathrm{~nm}$ recorded as a positive reaction. Purified LPS from Salmonella typhi 090 I (Difco Laboratories, Detroit, Michigan, U.S.A.) and Veillonella (Hofstad \& Kristoffersen, $1970 b$ ) were used as positive controls for heptose and KDO. The absorption spectra were recorded in a Unicam SP 800 spectrophotometer.

Paper chromatography. For demonstration of heptose samples were hydrolysed with $3 \mathrm{M}-\mathrm{HCl}$ for $3 \mathrm{~h}$ in an atmosphere of nitrogen at $100^{\circ} \mathrm{C}$. After removal of acid in vacuo at room temperature (approx. $22{ }^{\circ} \mathrm{C}$ ) in the presence of $\mathrm{NaOH}$ pellets, the samples were subjected to circular chromatography on Whatman no. I paper with $n$-butanol:pyridine: water (6:4:3 by vol.) and the dried chromatograms stained with aniline hydrogen phthalate (Partridge, 1949). 2-Keto-3-deoxy-octonate was sought in samples hydrolysed with $0.05 \mathrm{M}$ $\mathrm{H}_{2} \mathrm{SO}_{4}$ for 30 min and desalted by neutralizing with $\mathrm{Ba}(\mathrm{OH})_{2}$ followed by centrifuging and evaporation of the supernatant to dryness in vacuo. Chromatograms were run with $n$ butanol:pyridine: $0 \cdot \mathrm{I} \mathrm{M}-\mathrm{HCl}(5: 3: 2$ by vol.) as solvent. The thiobarbituric acid reagent of Warren (I960) was used to detect KDO. Salmonella typhi o90I LPS was included as a positive control.

Gas-liquid chromatography $(G L C)$. Samples hydrolysed in $0 \cdot \mathrm{I} \mathrm{M}-\mathrm{HCl}$ at $100{ }^{\circ} \mathrm{C}$ for $48 \mathrm{~h}$ were neutralized with Amberlite IRA $4 \mathrm{IO}, \mathrm{HCO}_{3}{ }^{-}$form, and the aldoses converted to alditol acetates by the method of Sawardeker, Sloneker \& Jeanes (1965). Gas-liquid chromatography was run in a Varian aerograph, Model I $520 \mathrm{~B}$ with a flame ionization detector, and fitted with a glass column $(0.32 \times 152 \mathrm{~cm})$ packed with $3 \%$ ECNSS-M $(w / w)$ on Chromosorb $\mathrm{Q}$, I00 to 120 mesh. The flow of gas $\left(\mathrm{N}_{2}\right)$ was $30 \mathrm{ml} / \mathrm{h}$ and the detector temperature 200 to $210{ }^{\circ} \mathrm{C}$. Samples ( $\left.\mathrm{I} \mu \mathrm{l}\right)$ of the alditol acetates in chloroform were injected. After elution of glucitol the initial isotherm column temperature of $170^{\circ} \mathrm{C}$ was raised to $190^{\circ} \mathrm{C}$. 


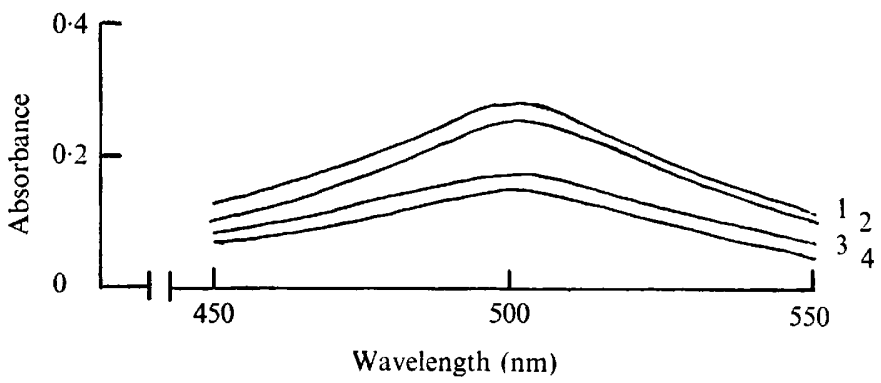

Fig. I. Absorption spectra in the Dische reaction of phenol phases from Staphylococcus NRRLB2628 (I), Bacteroides putredinium VPI4899-I (2), Bacteroides furcosus VPI3255 (3), and Lactobacillus La6i (4).

\section{RESULTS}

\section{Heptose}

In pilot experiments the absorption spectra given by samples of freeze-dried water phases from strains of Bacteroides and Fusobacterium in the Dische reaction for heptose and in the modified reactions were compared. The absorbance at 500 to $510 \mathrm{~nm}$, corresponding to heptose, was highest in the modified reactions, but tended to be obscured by the very high absorption at 400 to $450 \mathrm{~nm}$ given by 6-deoxysugars, which were present in most preparations. The procedure of Dische was therefore used in the final experiments.

Heptose was not detected in I to $2 \mathrm{mg}$ samples of freeze-dried water phases obtained by phenol water extractions of Bacteroides strains (Table I), nor in purified LPS. All the Bacteroides phenol phases gave an absorption peak at 500 to $505 \mathrm{~nm}$ in the sulphuric acidcysteine reaction of Dische. However heptose was not detected by paper chromatography of acid hydrolysates of the same phenol phases. Two strains of Lactobacillus, isolated from human saliva, and the Staphylococcus strain NRRLB2628 were then extracted with phenolwater. The phenol phases from all three strains gave an absorption peak at 500 to $505 \mathrm{~nm}$ in the Dische reaction (Fig. I), but heptose could not be demonstrated by paper chromatography. Finally, water and phenol phases from some Bacteroides strains were examined for neutral sugars by GLC. No trace of heptose was observed. The neutral sugars found were the same as those demonstrated by paper chromatography, namely galactose, glucose, fucose, rhamnose, trace amounts of mannose, and (in the water phase) ribose. Veillonella LPS was used as a positive control for heptose.

Water phases obtained from the Fusobacterium strains and from the two strains of Leptotrichia buccalis contained heptose. On chromatograms stained with aniline hydrogen phthalate the characteristic red-brown band corresponding to the heptose was located between the galactose and glucose bands.

\section{2-Keto-3-deoxy-octonate}

2-Keto-3-deoxy-octonate could not be demonstrated by the thiobarbituric acid reaction (3 $\mathrm{mg}$ samples) or by paper chromatography ( $2 \mathrm{mg}$ samples) in water phases obtained by extraction of the Bacteroides strains (Table 2) or in purified LPS. Freeze-dried water phases from Bacteroides strains VPIO950-I and VPI2368 produced a peak at 540 to $545 \mathrm{~nm}$ in the thiobarbituric acid reaction. Water phases from all Bacteroides strains gave an absorption peak at 530 to $535 \mathrm{~nm}$. None of the phenol phases $(5 \mathrm{mg}$ samples) reacted in the thiobarbituric acid reaction. 
Table 2. Distribution of KDO in phenol-water extracts of Bacteroides, Fusobacterium and Leptotrichia buccalis

\begin{tabular}{|c|c|c|c|c|}
\hline \multirow[b]{2}{*}{ Species } & \multirow[b]{2}{*}{ Strain } & \multicolumn{2}{|c|}{ Water phase } & \multirow{2}{*}{$\begin{array}{l}\text { Phenol phase } \\
\text { Thiobarbituric } \\
\text { acid reaction }\end{array}$} \\
\hline & & $\begin{array}{l}\text { Thiobarbituric } \\
\text { acid reaction }\end{array}$ & $\begin{array}{l}\text { Paper } \\
\text { chromato- } \\
\text { graphy }\end{array}$ & \\
\hline Bacteroides spp. & $*$ & - & - & - \\
\hline F. mortiferum & VPIO473 $=$ ATCC9817 & + & + & \\
\hline$F$. naviforme & VPI4877 & + & + & \\
\hline$F$. necrogenes & VPI2368 $=$ ATCC25556 & - & + & \\
\hline F. necrophorum & VPI6I6I & + & + & \\
\hline F. nucleatum & $\mathrm{VPI} 4355=\mathrm{ATCC} 25586$ & + & + & \\
\hline F. nucleatum & ATCCI0953 & + & + & \\
\hline$F$. plauti & VPI4I 45 & + & + & \\
\hline F. russi & VPIO307 & + & + & \\
\hline F. varium & VPIO499-A & + & + & \\
\hline F. varium & ATCC850I & - & + & \\
\hline L. buccalis & LIIT' & + & + & \\
\hline L. buccalis & $\mathrm{L} 66+$ & + & + & \\
\hline
\end{tabular}

Paper chromatograms of acid hydrolysates of the water phases from Fusobacterium strains gave a faint band with all strains, which had the same $R$ value as KDO released from S. typhi 090 I LPS, hydrolysed in the same way. A peak at $550 \mathrm{~nm}$ was not detected in the thiobarbituric acid reaction with the water phases from strains VPI2366 and ATCC850I. The peak produced by the other Fusobacterium strains was very small compared with the peak given by similar amounts of Veillonella LPS or water phases from the two Leptotrichia buccalis strains.

\section{DISCUSSION}

The outstanding feature of this study was the absence of heptose in phenol-water extracts of strains classified as Bacteroides. Heptose is absent also from lipopolysaccharides isolated from Neisseria catarrhalis (Adams, Tornabene \& Yaguchi, 1969), N. sicca (Adams, 1971), Moraxella duplex and Acinetobacter calcoaceticus (Adams, Quadling, Yaguchi \& Tornabene, 1970), Pseudomonas pavonacea (Wilkinson, Galbraith \& Lightfoot, 1973), Xanthomonas species (Volk, 1966) and myxobacteria (Rosenfelder, Lüderitz \& Westphal, 1974). In contrast, heptose was present in all strains of Fusobacterium examined and in Leptotrichia buccalis.

The chromatographic migration rate of the heptose was similar to that reported for L-glycero-D-mannoheptose (or D-glycero-D-mannoheptose) (Davies, I957), the aldoheptose commonly present in bacterial lipopolysaccharides.

Paper chromatography of acid hydrolysates was superior to the sulphuric acid-cysteine reaction for the demonstration of heptose. When heptose was present in small amounts with other sugars its absorption peak at $505 \mathrm{~nm}$ tended to be lost between the absorptions at 400 to $450 \mathrm{~nm}$ and 520 to $550 \mathrm{~nm}$ produced by deoxysugars and large amounts of glucose, respectively. Furthermore, the sulphuric acid-cysteine reaction apparently is not specific for heptose as materials recovered in the phenol phase also by extraction of Gram-positive bacteria gave positive reactions.

Acid-labile KDO was detected with difficulty in extracts from the Fusobacterium strains. Although the amounts of KDO in the water phases or in purified LPS were not quantified, 
comparison with Salmonella typhi 090 I and Veillonella LPS suggests that KDO is present in much smaller amounts in the LPS of Fusobacterium, as already reported by Kristoffersen \& Hofstad (1970), than in the LPS prepared from most other Gram-negative bacteria. It is possible, however, that during mild acid hydrolysis some of the KDO present was converted to derivatives which did not react with thiobarbituric acid (Volk, Salomonsky \& Hunt, 1972).

The Bacteroides species differed qualitatively from Fusobacterium species and Leptotrichia buccalis in containing no KDO in phenol-water extracts and LPS. KDO is absent from LPS isolated from Neisseria catarrhalis (Adams et al. 1969), Moraxella duplex and Acinetobacter calcoaceticus (Adams et al. 1970), Vibrio cholerae (Jackson \& Redmond, 197I) and from some Pseudomonas species (Wilkinson et al. 1973).

Because of the absorption given by deoxysugars at 530 to $535 \mathrm{~nm}$ in the thiobarbituric acid reaction, paper chromatography seems to be better suited for detection of KDO when present in small amounts in mixture with these sugars.

This study corroborates the generic separation of Fusobacterium and Bacteroides and extends the definition of these two genera and of Leptotrichia buccalis. The inclusion of Sphaerophorus strains in genus Fusobacterium (Sutcommittee, 1970) seems justified.

The taxonomy of anaerobic Gram-negative rods is at present based primarily on the production of fatty acids in glucose-containing media, and on other biochemical tests and susceptibility to antibiotics. Our findings show that analysis of wall components may also be used as a taxonomic criterion.

I am indebted to Dr Inge Fromme and Dr O. Lüderitz for advice and help with the GLC experiments, which were carried out during a visit to the Max-Planck-Institut für Immunbiologie, Freiburg, German Federal Republic. I am also grateful to Dr L. D. S. Smith for supplying the VPI strains.

\section{REFERENCES}

Adams, G. A. (I97I). Structural investigations on a cell-wall lipopolysaccharide from Neisseria sicca. Canadian Journal of Biochemistry 49, 243-250.

Adams, G. A., Tornabene, T. G. \& Yaguchi, M. (1969). Cell wall lipopolysaccharides from Neisseria catarrhalis. Canadian Journal of Microbiology 15, 365-374.

Adams, G. A., Quadling, C., Yaguchi, M. \& Tornabene, T. G. (I970). The chemical composition of cell-wall lipopolysaccharides from Moraxella duplex and Micrococcus calcoaceticus. Canadian Journal of Microbiology 16, I-8.

Anaerobe Laboratory Manual (1972). Edited by L. V. Holdeman and W. E. C. Moore. Blacksburg, Virginia, U.S.A.: V.P.I. Anaerobe Laboratory, Virginia Polytechnic Institute and State University.

Bergey's Manual of Determinative Bacteriology, 7th edn. (1957). Edited by R. S. Breed, E. G. D. Murray and N. R. Smith. Baltimore, Maryland, U.S.A.: Williams and Wilkins Co.

DAvies, D. A. L. (1957). The identification of aldoheptose sugars. Biochemical Journal 67, 253-256.

DisCHE, Z. (I953). Qualitative and quantitative colorimetric determination of heptoses. Journal of Biological Chemistry 204, 983-997.

HofSTAD, T. (1968). Chemical characteristics of Bacteroides melaninogenicus endotoxin. Archives of Oral Biology 13, I I49-1 155.

Hofstad, T. \& Kristoffersen, T. (1970a). Chemical characteristics of endotoxin from Bacteroides fragilis NCTC9343. Journal of General Microbiology 6r, I5-19.

HofsTAD, T. \& KRistoffersen, T. (1970 $b$ ). Chemical composition of endotoxin from oral Veillonella. Acta pathologica et microbiologica scandinavica $78 \mathrm{~B}, 760-764$.

HofSTAD, T. \& KRISTOFFERSEN, T. (I97I $a$ ). Lipopolysaccharide from Bacteroides melaninogenicus isolated from the supernatant fluid after ultracentrifugation of the water phase following phenol-water extraction. Acta pathologica et microbiologica scandinavica 79B, $12-18$. 
Hofstad, T. \& Kristoffersen, T. (197 I $b$ ). Preparation and chemical characteristics of endotoxic lipopolysaccharide from three strains of Sphaerophorus necrophorus. Acta pathologica et microbiologica scandinavica 79B, 385-390.

JACKsON, G. D. F. \& REDMOND, J. W. (I971). Immunochemical studies of the O-antigens of Vibrio cholerae. I. The constitution of a lipopolysaccharide from V. cholerae 569 B (Inaba). FEBS Letters I3, II 7-I 20.

Kristoffersen, T. \& HofSTAD, T. (1970). Chemical composition of lipopolysaccharide endotoxins from human oral fusobacteria. Archives of Oral Biology 15, 909-916.

Lüderitz, O., Staub, A. M. \& WestPhal, O. (I966). Immunochemistry of O and R antigens of Salmonella and related Enterobacteriaceae. Bacteriological Reviews 30, 192-255.

OsBorn, M. J. (1963). Studies on the Gram-negative cell wall. I. Evidence for the role of 2-keto-3-deoxyoctonate in the lipopolysaccharide of Salmonella typhimurium. Proceedings of the National Academy of Sciences of the United States of America 50, 499-506.

PARTRIdge, S. M. (I949). Aniline hydrogen phthalate as a spray reagent for chromatography of sugars. Nature, London 164, 443.

Rosenfelder, G., Lüderitz, O. \& WestPhal, O. (1974). Composition of lipopolysaccharides from $M y x o$ coccus fulvus and other fruiting and non-fruiting myxobacteria. European Journal of Biochemistry 44, $4 \mathrm{II}-420$.

SaWArdeker, J. S., Sloneker, J. H. \& Jeanes, A. (I965). Quantitative determination of monosaccharides as their alditol acetates by gas-liquid chromatography. Analytical Chemistry 37, 1602-1604.

SubcommitтeE (I970). Report of the International Committee of Nomenclature of Bacteria. Taxonomic Subcommittee for Gram-negative Anaerobic Rods. International Journal of Systematic Bacteriology 20, 297-300.

Volk, W. A. (1966). Cell wall lipopolysaccharides from Xanthomonas species. Journal of Bacteriology 9r, 39-42.

Volk, W. A., Salomonsky, N. L. \& Hunt, D. (1972). Xanthomonas sinensis cell wall lipopolysaccharide. I. Isolation of 4,7-anhydro- and 4,8-anhydro-3-deoxy-octulosonic acid following acid hydrolysis of Xanthomonas sinensis lipopolysaccharide. Journal of Biological Chemistry 247, 388I-3887.

Wahren, A. \& Gibbons, R. J. (I970). Amino acid fermentation by Bacteroides melaninogenicus. Antonie van Leeuwenhoek 36, I49-I59.

WARREN, L. (1960). Thiobarbituric acid spray reagent for deoxy sugars and sialic acids. Nature, London I86, 237.

WeissbaCh, A. \& Hurwitz, J. (1959). The formation of 2-keto-3-deoxyheptonic acid in extracts of Escherichia coli B. I. Identification. Journal of Biological Chemistry 234, 705-509.

WERNER, H. (1970). Glutaminsäuredecarboxylaseaktivität bei Bacteroides-Arten.Zentralblatt für Bakteriologie, Parasitenkunde, Infektionskrankheiten und Hygiene (Abteilung I) 215 A, 320-326.

Wilkinson, S. G., Galbraith, L. \& Lightfoot, G. A. (I973). Cell walls, lipids, and lipopolysaccharides of Pseudomonas species. European Journal of Biochemistry 33, I 58-174.

Wright, B. G. \& Rebers, P. A. (1972). Procedure for determining heptose and hexose in lipopolysaccharides. Modification of the cysteine-sulfuric acid method. Analytical Biochemistry 49, 307-3I9. 